\title{
REALISMO Y FANTÁSTICO EN LA LITERATURA ARGENTINA CONTEMPORÁNEA. EL PROBLEMA DE LOS GÉNEROS DESDE UNA PERSPECTIVA DERRIDEANA
}

\section{Realism and fantasy in contemporary Argentine literature. The problem of the genres from a derridean perspective}

\author{
Maia Bradford* \\ Universidad Nacional del Nordeste \\ maia_bfd@hotmail.com
}

Palabras clave

literatura argentina; fantástico; realismo; géneros; Derrida

\section{Keywords}

Argentine literature; fantastic; realism; genres; Derrida

\section{RESUMEN}

El trabajo parte de la observación de un movimiento del campo literario contemporáneo argentino: la aproximación del realismo y el fantástico a partir de cierta renovación en sus modos y contenidos. Una consideración más amplia de lo real, en el caso del realismo, y el alejamiento o abandono del componente necesariamente sobrenatural en el caso del fantástico, son aspectos centrales de estas trasformaciones genéricas. Ante esta evidencia, el artículo revisa y recupera la operatividad de la propuesta teórica de Jacques Derrida en su trabajo "La ley del género" acerca de la "participación sin pertenencia", esto es, la posibilidad de que los textos participen de los géneros sin pertenecer exclusivamente a ninguno, opción teórica que resulta un marco más amplio y, por lo tanto, más apropiado para pensar los modos literarios del presente.

\section{Abstract}

This work analyzes a movement in contemporary Argentine literature: the approach of realism and fantasy based on certain renewal of their modes and contents. Central aspects of these generic transformations are a broader consideration of the real, in the case of realism, and the estrangement or abandonment of the necessarily supernatural component in the case of the fantastic. Based on this evidence, this paper examines and recovers the operativeness of Jacques Derrida's theory in "The Law of Genre" about "participation without belonging". That is, the possibility that texts participate in genres without exclusively belonging to any of them, a theoretical option that results in a broader framework and, therefore, more appropriate for thinking about current literary modes. 


\section{Nuevos realismos y nuevos fantásticos}

Es conocida la tradición de los géneros miméticos que caracterizó durante mucho tiempo al campo literario y que asumía que la literatura era uno de los modos posibles de representar la realidad. Tal propósito guiaba los intentos de los artistas por captar el orden y el estado de las cosas que poblaban el mundo. Esta literatura, emparentada especialmente con el denominado "realismo clásico" decimonónico - mal entendido como costumbrismo mimético o transparencia ilusoria, según Sandra Contreras (2006) y Speranza (2005)-, si bien persiste aún en ciertas producciones de la narrativa argentina contemporánea, ha ido siendo reemplazada por "nuevos realismos", esto es, obras que, asumida la imposibilidad de la representación, parten de la resignificación de lo real para dar cuenta de las múltiples posibilidades hacia las que dicha noción se expande. Estos gestos y producciones obligan a la crítica a repensar la noción, la potencia y los alcances del realismo como lo muestran, entre otros, los trabajos de Contreras (2006), Speranza (2005), Kohan (2005) y Dalmaroni (2002).

Como explica Graciela Speranza (2005), entonces, a pesar de la sepultada "ambición ingenua de imitar o representar la realidad", convivirían en el amplio panorama de la literatura argentina contemporánea, autores, autoras y obras que, sin darse por enterados, insisten en dar batalla a la posibilidad de la mímesis, y otros que, en cambio y "anoticiados de la imposibilidad de tal empresa", habilitan la lectura de nuevos modos del realismo a partir de una reconfiguración de la noción de lo real. Esto supone, en consecuencia, una transformación en los modos de representarlo que pone en evidencia el carácter inestable del concepto y la apertura a lo que la autora llama "nuevas vías de exploración de lo real". En consonancia, afirma Contreras:

una lectura de "nuevos realismos" exige, hoy, justamente dar cuenta no sólo de nuevas formas de representación de la realidad - ¡como si la realidad pudiera representarse siempre del mismo modo!- sino antes bien de la transformación, en las nuevas coyunturas históricas, de la noción misma de "real". (2006, p. 8)

En el ámbito de los nuevos realismos este intento podría leerse, por ejemplo, en el caso de César Aira. Sandra Contreras (2006) encuentra en la obra del autor esta operación de "radical transfiguración del nudo formal del realismo", que consiste en el alejamiento de la trama contenida y la explosión del verosímil. Esto, afirma, puede ser leído como un salto o pulsión hacia lo real definido de un modo completamente novedoso. Se propone entonces, y en contraposición a la tradición clásica, esa precipitación y desborde del verosímil y, sobre todo y desde allí, la "ambición de tamaño inusitado" hacia lo real como marcas de un nuevo realismo y, por extensión, de un nuevo intento de exploración de lo real.

Estas consideraciones y nuestras lecturas del fantástico argentino contemporáneo nos conducen a pensar que un movimiento similar puede observarse en ese ámbito. Creemos que también allí conviven textos que se organizan desde las convenciones clásicas del género (Caillois, 1958; Vax, 1960; Todorov, 1970) y otros que se alejan de esa tradición, sin por ello distanciarse totalmente, a partir de nuevos modos de configurar lo fantástico. En este sentido, observamos en el panorama de la narrativa argentina contemporánea obras que, en algunos casos, responden a la lógica tradicional del fantástico, donde un evento sobrenatural irrumpe y enfrenta dos modos de consideración de lo 
real irreconciliables, lo posible y lo imposible, así como también existen otros casos en los que ese mismo enfrentamiento tiene lugar pero en ausencia del componente imposible. En estas últimas, el extrañamiento o enrarecimiento de la situación que el relato presenta, el vacío de sentido, resulta no de un hecho imposible sino de un gesto, elemento o situación perfectamente "normal" que pone en evidencia la posibilidad de que algo inesperado suceda. ${ }^{1}$

Aquí la convicción que está en el origen del fantástico permanece, aquella que asume que lo real es, en efecto, una construcción inestable de límites y formas difusas, un espacio caracterizado por la convivencia entre lo que tiene explicación y lo que no (cf. Roas, 2001), y por lo que Rabkin (1976) caracteriza como "lo antiesperado que ocurre". Lo que se modifica en ciertas formas que adopta el fantástico hoy son los modos a través de los cuales esa evidencia se pone de manifiesto. De maneras precisas, se "suaviza" aquello que suscita el efecto característico de estos relatos, lo que invita al lector a replantear su consideración sobre lo real. Ya lo fantástico no es solo el fantasma, el monstruo o la figura del doble sino, por ejemplo, la cotidianidad transformada por un vacío repentino, "algo" que debería estar y no está o, al contrario, un elemento, un gesto, una presencia en el lugar equivocado que pone en tensión al mundo narrado y al del lector. En este sentido, observamos una modificación en los contenidos de los eventos narrados y en las estrategias narrativas que evidencia una transformación del fantástico tradicional en el campo de la literatura argentina contemporánea.

A partir de la lectura y análisis de un corpus específico intentamos dar cuenta de un movimiento del campo literario: el realismo y el fantástico se aproximan, situándose ambas categorías en una nueva relación que supera los modos de lectura desde los que se los suele asumir como géneros cerrados y opuestos. Las transformaciones observadas tanto en los nuevos realismos como en un "nuevo fantástico" acentúan la imposibilidad de leer a partir de categorías estancas y contrapuestas y evidencian la necesidad de diferentes opciones teóricas para su abordaje.

\section{Lo fantástico: tradición y transformación}

¿Cuándo sucede lo fantástico? Según David Roas, "Lo fantástico se produce cuando nuestras convicciones sobre lo real dejan de funcionar" (2001, p. 95), cuando la historia narrada nos enfrenta con lo imposible: un evento improbable interviene la realidad que entonces se desestabiliza y aparece el temor. Pero para que tal efecto se suscite, como sostiene el autor, es necesario que el mundo narrado se presente gobernado por las mismas leyes que el del lector:

E1 relato fantástico sustituye la familiaridad por lo extraño, nos sitúa inicialmente en un mundo cotidiano, normal (el nuestro), que inmediatamente es asaltado por un fenómeno imposible -y, como tal, incomprensible- que subvierte los códigos -las certezas- que hemos diseñado para percibir y comprender la realidad. En definitiva, destruye nuestra concepción de lo real y nos instala en la inestabilidad y, por ello, en la absoluta inquietud. (Roas, 2011, p. 14)

1. Sugerí este movimiento del campo literario con anterioridad en el artículo "Poéticas de lo extraño: nuevos realismos/ nuevo fantástico en la literatura argentina contemporánea. Los casos de César Aira y Samanta Schweblin” en Expresiones del horror en la ficción hispánica de Patricia García y Teresa López Pellisa (2019). 
El choque entre lo posible y lo imposible en el orden de lo real es entendido como una percepción personal y subjetiva pero refrendada por lo colectivo. Allí reside la inquietud que lo fantástico genera y lo que impulsa al lector al cuestionamiento de su mundo. Así, el mundo tal cual lo conocemos muestra sus pliegues, sus infinitas posibilidades. Es claro, entonces, que la relación que se establece con la lectura del fantástico -y el realismo- no es entre el texto y la realidad sino entre este y una concepción de lo real, que dependerá de las coyunturas históricas. Como explica Rosalba Campra "las calificaciones de realista o fantástico aplicadas a un texto resultan necesariamente históricas, pues los sistemas convencionales -los códigos- no se pueden establecer de una vez para siempre y con igual validez para todas las latitudes" (2008, p. 18).

Si la historicidad de las formas se piensa y construye desde una historia cultural podemos afirmar que a diferentes coyunturas le corresponderán diferentes modos de representación. Asumimos aquí la historicidad que carga toda fantasía al llevar dentro de sí un registro de lo real. Desde estas consideraciones y nuestra lectura del fantástico contemporáneo, resulta evidente la transformación del género que pareciera haber ido apartándose de la norma, poniendo en entredicho la noción de un género que funciona por la presencia de lo sobrenatural.

Rosalba Campra (2008) observa esta transformación y caracteriza los modos de representar de lo fantástico. Encuentra cierto desgaste en los temas habituales; las criaturas y eventos que en esa tradición se constituían en eje del relato y suponían el umbral hacia lo desconcertante son sustituidos por ciertas rupturas en el nivel discursivo como el vacío o la falta de nexos entre elementos del mundo construido:

La transgresión de fronteras en el nivel semántico caracterizó lo fantástico clásico. La mayoría de los textos que adjudicamos a este género en el siglo pasado y en la primera mitad del XX, deben su inclusión a la presencia de vampiros, fantasmas, dobles, y seres diabólicos, casi todos dotados de las más interesantes perversiones. (...) Agotada, o por lo menos desgastada la capacidad de escándalo y desasosiego del tema fantástico, la transgresión se expresa a través de roturas en la organización de los contenidos, no necesariamente fantásticos. Es decir, su manifestación puede rastrearse fundamentalmente en el nivel sintáctico: la aparición del fantasma ha sido sustituida con la irresoluble falta de nexos entre los elementos de la pura realidad. (p. 135-136)

De esta manera la autora explica la sustitución de los modos adoptados por el fantástico, antes caracterizado por la presencia de ciertos elementos en el mundo narrado, en el nivel semántico, y ahora reemplazados por innovaciones en el nivel sintáctico. "Contenidos no necesariamente fantásticos" aparecen estructurando el relato que, a pesar de ello, mantiene su efecto de lectura característico.

Desde estas consideraciones, es evidente que el marco que desarrolla y recupera la tradición teórica "clásica" del fantástico pierde alcances para dar cuenta de la novedad de una zona de sus manifestaciones contemporáneas.

Las sucesivas relecturas críticas de la publicación del texto Introducción a la literatura fantástica de Todorov en 1970 renovaron la discusión sobre los alcances de la caracterización genérica de la literatura fantástica. A partir de ese momento surgieron en el escenario académico europeo y latinoamericano propuestas que demuestran la fertilidad de la discusión y la amplitud de las opciones teóricas al considerar lo fantástico desde categorías tales como "modo de representación”, en palabras 
del propio Todorov, "género" (Barrenechea, 1985), "tipo ficcional” (Reisz, 2001), “categoría transversal a los géneros”(Barrenechea, 1991), "lógica narrativa” (Bessière, 1974), "perspectiva narrativa” o "modo" (Jackson, 1981), “construcción discursiva” (Arán, 1999), “género” o “categoría” (Roas, 2001, 2006) o "modo narrativo" (Quereilhac, 2016).

Existe cierto consenso dentro de la crítica argentina en situar en la década del cuarenta del pasado siglo el origen de la literatura fantástica en nuestro país a partir de las publicaciones de escritores cercanos al grupo Sur: Jorge Luis Borges, Adolfo Bioy Casares, José Bianco y la escritora Silvina Ocampo (Gamerro, 2010). No obstante, otras posiciones (Quereilhac, 2016) indican que podemos considerar el desarrollo de este tipo de ficciones ya en el último tercio del siglo XIX a partir de ciertos textos de Leopoldo Lugones, Horacio Quiroga, Eduardo Holmberg, entre otros. Más atrás o más adelante en el tiempo, lo cierto es que luego de ese momento de consolidación, la literatura fantástica continuó su curso. Así, lo fantástico, desde una consideración amplia y de límites borrosos, ha sido el modo de ficción elegido por autores y autoras como Marco Denevi, Julio Cortázar, Antonio Di Benedetto, Abelardo Castillo, Elvio Gandolfo, Angélica Gorodischer o Ana María Shua, que en gran parte de sus producciones literarias eligieron modulaciones diferentes del género.

Desde esta tradición, observamos en cierta zona de la literatura argentina contemporánea lo que consideramos una preferencia por lo fantástico en variados modos o formas. Refrendan esta consideración voces como la de Ana María Shua (2016) que propone una "renovación del género que están logrando hoy los jóvenes escritores argentinos, llevando la tradición de lo fantástico por nuevos derroteros" (párr. 16). Consideramos dentro del amplio espacio de lo fantástico, entre otras, las narraciones de Samanta Schweblin, Mariana Enríquez, Federico Falco, Luciano Lamberti, Mariano Quirós, Iosi Havilio, Hernán Vanoli, Roque Larraquy, Diego Muzzio, Leonardo Oyola, Gabriela Cabezón Cámara, Dolores Reyes y Camila Sosa Villada.

¿Qué características son reconocibles en tal renovación? ¿En qué consiste? ¿Qué se repite y qué se desplaza en los textos fantásticos del presente? Como hemos adelantado, entre las características que nos interesan, observamos en algunos de los autores y autoras mencionados una intensificación de lo cotidiano en la construcción de lo fantástico o cierta cotidianización de lo insólito: lo sobrenatural pierde fuerza frente a lo habitual que aparece, eso sí, modificado, desencajado por un elemento o evento conocido pero que allí no pertenece y desconcierta. Así, estos modos renovados del fantástico ya no intentan destruir nuestra percepción de lo real sino corroborar o confirmar su extrañeza intrínseca.

Además de la incorporación de elementos no necesariamente fantásticos, encontramos también en esta renovación una modificación en la relación con los hechos y en la reacción de los personajes ante los eventos narrados. En los personajes que vivencian la ruptura del orden racional no hay desquicio, a diferencia de la tradición clásica del fantástico aquí no hay pérdida de la razón ni reacciones desmesuradas. Los personajes parecen aceptar con cierta resignación los diferentes pliegues de lo real, o al menos estar preparados para hacerlo. En algunos casos, frente a la evidencia de "lo que no puede ser", actúan hasta como si ya lo supieran, como si solo confirmaran una sospecha que desde hace tiempo los interpela. "Extraño puede ser muy normal", sostiene una de las protagonistas de Distancia de rescate (2015), nouvelle de Samanta Schweblin. El mundo, con 
sus múltiples posibilidades, con sus excepciones, puede ser tolerable. Encontramos en palabras de la propia autora la justificación de esta nueva torsión del fantástico, "Cuanto más se acerca un texto a la realidad, más extraño se vuelve. El género fantástico ya no es Frankenstein. Ahora, es también la posibilidad de algo terrible" (2009, párr. 4). En otra entrevista, dice también Schweblin:

Sigo en mi idilio con la literatura fantástica, pero estoy descubriendo que, si escribo desde el límite del realismo con lo fantástico, se abren nuevas veredas. Contar lo anormal desde lo normal hace que la amenaza se vuelva más cercana, renueva la tensión. (2015, párr. 2)

\section{El problema de la hibridación genérica}

María Celeste Aichino (2014) aborda en su trabajo los efectos de lectura de dos autores considerados por buena parte de la crítica como "realistas", Marcelo Cohen y Alberto Laiseca, y propone que sus escrituras, sin embargo, contienen elementos que podrían pensarse como propios del fantástico. Recuerda que son los mismos autores quienes califican a sus literaturas como "realismo incierto" (o inseguro) y como "realismo delirante", respectivamente. Sobre Cohen, Aichino sostiene:

lo fantástico en las narraciones de Marcelo Cohen no se manifiesta en lo sobrenatural o en lo extraño que irrumpe en lo cotidiano, en lo real, sino en la sensación de extrañamiento que genera lo real mismo, en la imposibilidad que encuentran, aunque sea momentáneamente, los personajes para darle sentido a la experiencia, a lo real inmediato que les toca vivir. $(2014$, p. 8)

Observamos aquí un planteamiento coincidente, según nuestra perspectiva, con el que creemos que caracteriza al menos a cierta zona del fantástico contemporáneo.

La lectura de artículos en los que la crítica argentina discute los alcances de la categoría de realismo y analiza sus manifestaciones más actuales, sumado a nuestro interés por el fantástico argentino contemporáneo, nos han conducido a espacios de contacto entre dos de las categorías desde las que tradicionalmente se piensa la literatura. Los cuestionamientos surgidos señalaban una situación paradójica que remitía a interrogantes como: ¿por qué donde algunos leen realismos otros, fantástico?, ¿por qué hay ciertas obras que presentan elementos tradicionalmente fantásticos y son sin embargo leídas como realistas?, ¿qué diferencia al "realismo delirante" o al "realismo incierto o inseguro" del "nuevo" fantástico?

Comenzamos este trabajo haciendo referencia a las lecturas renovadas que desde hace un tiempo viene ofreciendo la crítica argentina acerca de los nuevos realismos, esto es, "personalísimos" modos del realismo contemporáneo del cual César Aira sería un caso ejemplar. Hemos sugerido la relación de estos nuevos realismos con obras que configuran lo fantástico de una forma también renovada. Si el realismo "salta" hacia lo real, asume el desborde para poner en evidencia los intersticios por donde se cuela lo extraño que subyace en lo real; si, por su parte, y retomando el planteamiento

2.La expresión aparece en el artículo de Contreras (2006) cuando recupera la lectura del realismo propuesta por Sergio Delgado (2005). 
inicial, la transgresión propia del fantástico mantiene el recurso a lo inusitado pero ya no toma la forma de la criatura extraña sino es ahora la posibilidad de algo terrible, sustituyendo así la tradicional presencia de lo sobrenatural por elementos propios de lo real, entonces ¿¿cómo leer críticamente estas obras?, ¿desde qué paradigmas analizarlas?

El alejamiento o abandono de lo sobrenatural en el caso del fantástico, la ampliación de lo real hacia zonas indefinidas o irreales en el del realismo, invitan a repensar la clásica dicotomía y la cuestión de los géneros y sus reglas e implicancias. Si recapitulamos, podemos afirmar que hoy el realismo no es la novela decimonónica y el fantástico no es Frankenstein. Sin embargo, para repensar estas reconfiguraciones tampoco resulta pertinente sustituir esas definiciones por otras igualmente estrictas. Es evidente que no se puede referir a estas categorías de manera restringida. La literatura contemporánea nos sitúa frente a la dificultad de definir categorías de amplio alcance.

De este modo, frente al desafío teórico de encontrar una categoría o re-uso categorial que pueda dar cuenta de nuestra zona de interés, las que consideramos nuevas formas de manifestación de lo fantástico en la literatura argentina contemporánea, nos encontramos con la productividad de la propuesta de Derrida acerca de cómo pensar la noción de género.

\section{Participación sin pertenencia, la opción teórica de Derrida}

Sostener que se aborda la propuesta teórica de Derrida resulta siempre un gesto tan inexacto como excesivo. Por ello ofrecemos, desde nuestros intereses y en el marco del problema hasta aquí presentado, un intento por recorrer parte de uno de los hilos del tejido de su trama compuesta por textos que combinan acercamientos y distancias de las convenciones académicas, sondean los límites de ese campo, se mueven en los márgenes siempre borrosos de la filosofía y la literatura, sostenidos en la exploración de las posibilidades de la escritura y sus efectos.

Desde esta escritura singular, en algunos de sus textos aparecen protocolos académicos esperables pero en su gran mayoría tales expectativas se desarman tras los primeros renglones. Se trata de operaciones de escritura que sustentan operaciones críticas. Así, al desacomodar al lector desde la utilización del lenguaje, señala la improductividad de ciertos espacios "ganados" del saber científico y de sus convenciones y movimientos siempre previsibles.

Si podemos hablar de ejercicios de lectura y escritura en Derrida (cf. Gerbaudo, 2006) es porque su obra -no solo sus escritos sino sus "actuaciones" y sus decisiones políticas en relación con la institución literatura- configura una verdadera epistemología, que se formula a partir de lo que Analía Gerbaudo (2006) llama intervenciones: "no sólo el anuncio de otra filosofía sino la puesta en práctica de un nuevo modo de ejercitarla que supone, a la vez, un nuevo modo de leer los textos y de escribir esa lectura de los textos" ${ }^{3}$ (párr. 56). Esta lectura se concibe como la decisión de seguir uno de los muchos

3. La necesaria inauguración de una marca, de una nueva forma de lectura ante una nueva forma escritura, supone, sin dudas, un acto político. El amplio alcance de estas decisiones y prácticas es descrito por Gerbaudo (2006) en los 
hilos posibles de la trama textual, entregarse a la experiencia de lo desconocido, seguir el pensamiento que, según Jorge Panesi (2008) se concibe como "estrategias siempre variables sin destino prefijado, como un cálculo incesante ante lo incalculable, destino errático que llamó destinerrancia" (p. 85); concepto que el propio Derrida (2001) definió como "la posibilidad que tiene un gesto de no llegar nunca a su destino, es la condición del movimiento de deseo que, de otro modo, moriría de antemano” (p. 42).

El carácter singular de sus textos hace imposible el hallazgo de alguno que condense sus principales categorías, sus conceptos fundacionales, y vuelve necesaria la labor de una especie de "lectura total" de su obra, modo posible de acercarse a la reconstrucción de tales conceptos y de su programa (cf. Gerbaudo, 2009). Por ello, el objetivo de este apartado es modesto: nos proponemos abordar las posibilidades de re-uso de su propuesta sobre la categoría de género en el marco de las discusiones sobre el fantástico y el realismo antes presentadas.

En "La ley del género" (1980) ${ }^{4}$ Derrida realiza una de sus habituales "operaciones de lectura" sobre La folie du jour de Blanchot, autor cuya obra narrativa fue abordada detenidamente por Derrida en varios de sus textos. ${ }^{5}$ Como Ponge, como Borges, Celan o Joyce -los autores sobre los que el filósofo francés decide escribir- Blanchot persigue el deseo de generar un acontecimiento, de dejar, a partir de su escritura, marcas en la lengua. ${ }^{6}$ Por eso decide contrafirmar esos textos con su lectura.

Derrida propone categorías a partir de sus intervenciones sobre los textos literarios que elige por considerarlos potentes, textos que

tienen en común el estar todos ellos inscritos en una experiencia crítica de la literatura. Contienen todos en sí mismos, o podría decirse también, ponen a trabajar en su acto literario, una pregunta, la misma, pero singular en cada ocasión y puesta a trabajar de un modo distinto: “¿qué es la literatura?" o “¿de dónde viene la literatura?”, “¿qué debemos hacer con la literatura?”. (2017, p. 122)

En "Esa extraña institución llamada literatura", Derrida sostiene que lo que caracteriza a la literatura es "cierta promesa de poder decirlo todo" (2017, p. 120). Ahora bien, ¿cómo se organizan los resultados de esa posibilidad infinita? Derrida no asume la autonomía de la literatura sino que la piensa como institución literaria, es decir, en estrecha relación y dependencia de la cultura, la historia,

siguientes términos: "Este gesto de ruptura con el estado de cosas existente en el campo de la lectura de los textos y de la escritura de la lectura de los textos, esta 'poética' supone una 'política' que, lejos de perpetuar los consensos, hace visible otra posibilidad, otra perspectiva de trabajo. Es político hacer notar que aquello que se hace de un modo puede hacerse también de otra manera y que esa otra manera, usualmente descartada por las comunidades de práctica, no obstante puede ser potente en términos cognitivos. Discutir no sólo una formulación sino el modo de escribirla constituyen formas de trabajar en la construcción del conocimiento. Éste es el acto político crucial que, sin estridencias, practica la desconstrucción derrideana" (párr. 56).

4. “La loi du genre”, publicado en Glyph, 7, Baltimore, Johns Hopkins University Press, 1980. Para este trabajo he utilizado la traducción de Ariel Schettini para la cátedra Teoría y Análisis literario de Jorge Panesi, UBA-FFyL, s/f.

5. Además de "Le loi du genre”, Glyph 7 (1980), entre otros en Parage (1986), “Demiure: fiction et temoignage”, en Passions de la littérature (1996).

6. Intención o asunción compartida con el propio Blanchot que sostiene en "La literatura y el derecho a la muerte" en $D e$ Kafka a Kafka (1981) “¿qué hace el escritor que escribe? (...) Escribe a partir de cierto estado del lenguaje, de cierta forma de la cultura, de ciertos libros, también a partir de elementos objetivos, tinta, papel, imprenta. Para escribir, le es preciso destruir el lenguaje tal como es y realizarlo en otra forma, negar los libros haciendo un libro con lo que no son" (p. 16). 
la política, las otras instituciones del espacio social. Se trata, entonces, de una institución ligada a una organización política que la hace posible, la democracia (entendida como promesa, como por-venir):

Esa institución ficticia que en principio confiere el poder de decirlo todo, de liberarse de las reglas, de desplazarlas, y por consiguiente de instituir, de inventar e incluso de arrojar sospechas sobre la tradicional diferencia entre naturaleza e institución, naturaleza y ley convencional. Debemos aquí formularnos interrogantes jurídicos y políticos. La institución de la literatura en Occidente, en su forma relativamente moderna, está ligada a una autorización para decirlo todo y, sin duda, al advenimiento de la idea moderna de democracia. No es que dependa de una democracia ya instalada, pero me parece inseparable de lo que convoca una democracia, en el más abierto y sin duda aún por llegar sentido de democracia. (2017, p. 118)

Desde esta concepción institucional de la literatura aparece su relación con la ley, con las normas o convenciones, implícitas o explícitas, que regulan los modos de leer y escribir, de producir y leer literatura. Condición institucional que afecta a la obra: "Si bien el espacio institucional o sociopolítico de producción literaria, en cuanto tal, es reciente, este no se limita simplemente a rodear a las obras, las afecta en su misma estructura" (2017, p. 120). Como hemos señalado, estas consideraciones acerca de los límites inevitablemente borrosos de las formas textuales, se observa en su propia escritura. Operaciones como las de Glas (1974) evidencian que Derrida “actúa sus propias tesis", como explica Analía Gerbaudo:

Texto escrito desde protocolos que desconciertan todo intento de ubicación segura en un género: la barra que separa filosofía de literatura se vuelve borrosa. Los cuerpos genéricos se muestran contagiándose, contaminándose, intercruzándose... Y justamente esta explotación de la hibridez genérica interroga a los estudios teóricos enmarcados en las 'ciencias humanas' en su punto de confluencia, es decir, en el intento de mantenerse al resguardo bajo la pureza de las leyes del género. (2006, párr. 18)

Desde estas intenciones, Derrida se pregunta por la ley que hay detrás de la ley del género. Afirma que hablar de género es apelar a la ley, a cuestiones jurídico-históricas relacionadas con el texto.

Su texto "Le loi du genre" (1980) comienza con las afirmaciones irónicas: "No mezclar los géneros. No mezclaré los géneros. Repito: No mezclar los géneros. No lo haré” (p. 2). Frente a estas afirmaciones, Derrida presenta dos posibilidades de hipótesis. Las llama géneros de hipótesis y serían: o bien asumir que se trata de proposiciones descriptivas, constatativas, un discurso neutro que supone "lo que sin duda tendrá lugar", o bien interpretar la afirmación "como una orden abreviada":

A partir del momento en que se escucha la palabra 'género', desde que aparece, desde que se lo intenta pensar, se dibuja un límite. Cuando se asigna un límite, la norma y lo prohibido no se hacen esperar: 'Hay que, no hay que', dice el 'género', la palabra 'género', la figura, la voz o la ley del género. (...) Así, desde que un género se anuncia, hay que respetar una norma, no hay que franquear una línea limítrofe, no hay que arriesgarse a la impureza, la anomalía o la monstruosidad. (1980, p. 2-3)

Sin embargo, al ser la propia ley la que ordena no mezclar los géneros es el mismo discurso de la ley el que engendra la posibilidad de una contra-ley. Entonces, existiría otra opción: 
A menos que, más que un compromiso, se trate de una parada, de un desafío, de una apuesta imposible. ¿Y si fuera imposible? ¿No mezclar los géneros? ¿Y si se hallaran alojados en el corazón de la ley misma, una ley de impureza o un principio de contaminación? ¿Y si la condición de posibilidad de la ley fuera el a priori de una contra-ley, un axioma de imposibilidad que enloqueciera el sentido, el orden y la razón? (1980, p. 3-4)

Esta impureza o principio de contaminación sería, así, inherente a la propia ley. Se trata de una "contra-ley que la constituye y la vuelve posible, la condiciona y se vuelve inabordable e indesbordable, incontornable por razones de bordes, sobre los que inmediatamente iremos a parar" (1980, p. 4). A partir de allí Derrida enuncia lo que denomina "la ley de la ley del género":

Es precisamente un principio de contaminación, una ley de impureza, una economía del parásito. En el código de la teoría de los conjuntos, si me transportara al menos figuralmente, hablaría de una suerte de participación sin pertenencia. El rasgo que marca la pertenencia se divide ineludiblemente el borde del conjunto forma por invaginación un bolsillo interno más grande que el todo: las consecuencias de esta división y de este desborde son tan singulares como ilimitadas. (1980, p. 5)

Anticipa así su hipótesis principal: la hibridación, la contaminación, la monstruosidad o el desborde son la condición de posibilidad de la ley y de los textos. Llegado a este punto, Derrida presenta en términos generales una afirmación de $\mathrm{Genette}^{7}$ que retoma la oposición entre naturaleza e historia y explica un equívoco generalizado: "se han considerado naturales estructuras o formas típicas cuya historia es tan poco natural como posible” (1980, p. 6). Esto le permite a Genette afirmar la naturalización de los géneros. Derrida recupera del autor la siguiente cita:

La historia de la teoría de los géneros está marcada por esquemas fascinantes que informan y deforman la realidad a menudo heteróclita del campo literario y pretenden descubrir un 'sistema' natural allí donde construyen una simetría artificial con gran refuerzo de falsas aberturas. (Genette en Derrida, 1980, p. 6)

Derrida cree que desde esta oposición planteada (aunque, según él, no lo suficientemente profundizada) "queda abierto un espacio tanto a cuestiones preliminares sobre sus suposiciones, como a preguntas acerca de los bordes donde esta lectura comienza a tomar amarras. Es la forma de esos bordes lo que me retendrá" $(1980$, p. 8$)$.

Para detenerse en esos bordes elige el libro La folie du jour de Maurice Blanchot porque "parece hecho, entre otras cosas, para servirse de todas las categorías tranquilas de la teoría y de la historia de los géneros para inquietar sus seguridades taxonómicas, la distribución de sus clases y las nominaciones controlables de sus nomenclaturas clásicas" (Derrida, 1980, p. 9). Desde este abordaje, anuncia, "sobre el borde liminal de la historia (y) de la teoría de los géneros" lo que llama "la ley de desborde, de participación sin pertenencia, de contaminación, etc.” (p. 9). Múltiples nombres para una ley detrás de la ley que hace posible lo imposible, alberga o habilita las diversas realizaciones de textos literarios que participan de distintos géneros sin pertenecer absolutamente a ninguno. Enuncia así su propuesta:

7. “Géneros, tipos, modos” de G. Genette, publicado en Poétique, 32, titulado “Géneros” (1977). 
un texto no pertenecería a ningún género. Todo texto participa de uno o varios géneros, no hay texto sin género, siempre hay género y géneros, pero esta participación no es jamás pertenencia. Y esto no ocurre a causa de un desborde de riqueza o libre productividad anárquica e inclasificable, sino a causa del mismo rasgo de participación, del efecto del código y de la marca genérica. (...) Este axioma de no-clausura o de incompletud, lleva en sí la condición de posibilidad y de imposibilidad de una taxonomía. Esta inclusión y esta exclusión no son exteriores una en relación a la otra, no se excluyen. (1980, p. 10-11)

La fórmula "participación sin pertenencia" (participation sans appartenance) da cuenta así de la hibridación propia de todo género, del modo en que los textos se relacionan con las clasificaciones genéricas.

\section{A modo de cierre}

Desde el planteamiento general del problema que hemos abordado, encontramos en la propuesta de Derrida sobre el género un aporte valioso. Frente a la dificultad que supone hallar categorías operativas para pensar los renovados modos en los que se configuran ciertas zonas de la literatura argentina contemporánea surge la convicción de la necesaria sustitución de la noción de "pertenencia" de determinadas obras en relación con los géneros por la de "participación". Como sostiene Aichino (2014) no tiene sentido organizar una lista de atributos "realistas" -o "fantásticos", agregamos nosotros- y pretender adjudicársela a cierta producción actual ni tampoco rastrearla allí. Al contrario, y como hemos intentado mostrar en este trabajo, resulta operativa la propuesta derrideana de una participación de los textos del realismo por sobre una pertenencia a dicha estética, "pero de una manera no ingenua sino problematizada por las diversas crisis políticas, científicas, económicas y sociales que marcan nuestro tiempo. Realistas, sí, pero también fantásticos, terroríficos, irracionales, grotescos, delirantes" (Aichino, 2014, p. 16).

De este modo, se trataría de partir de las reconfiguraciones de las formas clásicas, tanto del realismo como del fantástico y apelar a las categorías tradicionales para reconsiderar sus caracterizaciones. Circunscribir, entonces, dichas categorías al ámbito de las discusiones abiertas y proponer el modo singular en que ciertas obras se relacionan o participan de esas categorías.

Este trabajo da cuenta de un movimiento del campo literario a la vez que intenta esbozar una cartografía de la narrativa argentina contemporánea alrededor del problema del fantástico mostrando sus matices y su carácter rugoso, en absoluto homogéneo. En tal sentido, recuperamos la operatividad de la propuesta derrideana de la participación sin pertenencia, ante la necesidad de trascender las barreras de las concepciones estancas sobre los géneros, ya que suponen modos de pensar que, como lo demuestra Derrida con sus intervenciones - dentro y fuera de los textos- resultan más propicios para aproximarnos a la siempre inasible literatura. Por último, se desprende del planteo otra sugerencia vital del pensador francés para nuestro campo de estudio, la necesidad de que quienes pensamos la literatura también actuemos nuestras propias tesis. 


\section{Referencias bibliográficas}

Aichino, M. C. (2014). Teorías del fantástico y nuevos realismos. Reflexiones acerca de potenciales efectos de lectura en algunas obras de Alberto Laiseca y Marcelo Cohen. Recial, 5 (5-6), 1-21. https://bit.ly/2P2b3IV

Arán, P. (1999). El fantástico literario. Aportes teóricos. Córdoba, Narvaja.

Barrenechea, A. M. (1985). La literatura fantástica: función de los códigos socioculturales en la constitución de un género. En: El espacio crítico en el discurso literario (pp.45-54). Buenos Aires, Kapeluz.

Barrenechea,A.M.(1991). El género fantástico entre los códigos y los contextos. En: Morillas Ventura, E. (ed.), El relato fantástico en España y Hispanoamérica (pp. 75-81). Madrid, Siruela.

Bessière, I. (1974). Le récit fantastique. La poétique de l'incertain. París, Larousse.

Blanchot. M. (1981). La literatura y el derecho a la muerte. En: De Kafka a Kafka (pp. 5-37). México, Fondo de Cultura Económica.

Bradford, M. (2019). Poéticas de lo extraño: nuevos realismos/nuevo fantástico en la literatura argentina contemporánea. Los casos de César Aira y Samanta Schweblin. En: García, P. y López Pellisa, T. (coords.). Expresiones del horror en la ficción hispánica (pp. 35-52). Madrid, Aluvión.

Caillois, R. (1958). Del cuento de hadas a la ciencia ficción. En: Imágenes. Imágenes (pp. 9-47). Barcelona, Edhasa.

Campra, R. (2008). Territorios de la ficción. Lo fantástico. Madrid, Renacimiento.

Contreras, S. (2006). Discusiones sobre el realismo en la narrativa argentina contemporánea. Orbis Tertius, 11 (12), 1-16. https://bit.ly/3ggaZAJ

Dalmaroni, M. (2002). El imperativo realista y sus destiempos. En: Gramuglio, M. T., El imperio realista (pp. 441-468). Ciudad Autónoma de Buenos Aires, Emecé. En: https://bit.ly/3jhpGFt

Derrida, J. (1974). Glas. Paris, Denoë1/Gonthier.

Derrida, J. (1980). La ley del género (A. Stecchini, trad.). Ciudad Autónoma de Buenos Aires, Universidad de Buenos Aires. https://bit.ly/2X1scac

Derrida, J. (2001). A corazón abierto. En: ¡Palabra! Instantáneas filosóficas (De Peretti, C. y Vidarte, P., trad.) (pp. 13-48). Madrid, Trotta.

Derrida, J. (octubre de 2017). Esa extraña institución llamada literatura. Una entrevista de Derek Attridge con Jacques Derrida (V. Tuset, trad.). Boletin, 18, 115-150.

Gamerro, C. (2010). Ficciones barrocas. Una lectura de Borges, Bioy Casares, Silvina Ocampo, Cortázar, Onetti y Felisberto Hernández. Ciudad Autónoma de Buenos Aires, Eterna Cadencia.

Genette, G. (1977). Genres, 'tipes', modes. Poétique, 32, 389-421.

Gerbaudo, A. (2006). La literatura en el proyecto teórico y político de Derrida: una lectura. Espéculo. Revista de estudios literarios, 32. https://bit.ly/2Q3LFDc

Gerbaudo, A. (2009). Plus d'un Derrida. Notas sobre desconstrucción, literatura y política. Espéculo. Revista de estudios literarios, 41. https://bit.ly/3iSSFzi 
Jackson, R. (1981). Fantasy, the literature of subversion. Nueva York, New Accents.

Kohan, M. (2005). Significación actual del realismo críptico. Boletin, 12, 246-264.

Panesi, J. (2008). Variaciones sobre la literatura: la inscripción autobiográfica. En: Cragnolini, M. (Comp.). Por amor a Derrida. Ciudad Autónoma de Buenos Aires, La Cebra.

Quereilhac, S. (2016). Cuando la ciencia despertaba fantasias. Ciudad Autónoma de Buenos Aires, Siglo Veintiuno.

Rabkin, E. (1976). The Fantastic in Literature. New Jersey, Princeton University.

Reisz, S. (2001). Las ficciones fantásticas y sus relaciones con otros tipos ficcionales. En: Roas, D. (ed.). Teorías de lo fantástico (pp. 193-222). Madrid, Arco.

Roas, D. (ed.) (2001). Teorías de lo fantástico. Madrid, Arco.

Roas, D. (2006). Hacia una teoría sobre el miedo y lo fantástico. Semiosis, II (3), 95-116.

Roas, D. (2011). Tras los límites de lo real. Una definición de lo fantástico. Madrid, Páginas de Espuma.

Schweblin, S. (20 de junio de 2009). Un mundo extraño y perturbador (Entrevista). La Nación. https:// bit.ly/3anNzYQ

Schweblin, S. (9 de abril de 2015). Samanta Schweblin gana el Premio Ribera del Duero 'desde el límite de lo fantástico y el realismo' (Entrevista). El Mundo. https://bit.ly/3al3GWU

Schweblin, S. (2015). Distancia de rescate. Barcelona, Literatura Random House.

Shua, A. M. (20 de mayo de 2016). Literatura fantástica argentina. Evaristo Cultural. https://bit. 1y/3iCemTT

Speranza, G. (diciembre de 2005). Por un realismo idiota. Boletín, 12, 1-11. https://bit.ly/2Q4ongE Todorov, T. (2006). Introducción a la literatura fantástica. México, Seuil (original publicado en 1970). Vax, Louis. (1960). L'Art et la Littérature Fantastique. Paris, Presse Universitaire de France.

Williams, R. (1977). Marxismo y literatura. Barcelona, Península.

*Maia Bradford es Profesora en Lengua y Literatura y Licenciada en Letras (Universidad Nacional del Nordeste) y Máster en Investigación en Letras y Humanidades (Universidad de Castilla-La Mancha, España). Es Profesora Adjunta en las Teoría Literaria y Literatura y cine(UNNE). Actualmente desarrolla su tesis doctoral titulada "Narrativas de lo insólito en la literatura argentina contemporánea (2001-2019)", en el marco del Doctorado en Letras de la UNNE.

RECEPCIÓN: 08/02/2020

ACEPTACIÓn: 05/06/2020 